\title{
Prognosis of Elderly Japanese Patients Aged $\geq 80$ Years Undergoing Hemodialysis
}

\author{
Shingo Hatakeyama, ${ }^{1}$ Hiromi Murasawa, ${ }^{1}$ Itsuto Hamano, ${ }^{1}$ Ayumu Kusaka, \\ Takuma Narita, ${ }^{1}$ Masaaki Oikawa, ${ }^{1}$ Daisuke Noro, ${ }^{1}$ Kazuhisa Hagiwara, ${ }^{1}$ \\ Hirofumi Ishimura, ${ }^{2}$ Takahiro Yoneyama, ${ }^{1}$ Yasuhiro Hashimoto, ${ }^{3}$ Takuya Koie, \\ Hisao Saitoh, ${ }^{2}$ Tomihisa Funyu, ${ }^{2}$ and Chikara Ohyama ${ }^{1,3}$ \\ ${ }^{1}$ Department of Urology, Hirosaki University Graduate School of Medicine, 5 Zaifu-chou, Hirosaki 036-8562, Japan \\ ${ }^{2}$ Department of Urology, Oyokyo Kidney Research Institute, Hirosaki 036-8243, Japan \\ ${ }^{3}$ Department of Advanced Transplant and Regenerative Medicine, Hirosaki University Graduate School of Medicine, \\ Hirosaki 036-8562, Japan \\ Correspondence should be addressed to Chikara Ohyama; coyama@cc.hirosaki-u.ac.jp
}

Received 5 August 2013; Accepted 3 September 2013

Academic Editors: R. Ando, F. Hinoshita, S. Kuriyama, and R. Sakai

Copyright (c) 2013 Shingo Hatakeyama et al. This is an open access article distributed under the Creative Commons Attribution License, which permits unrestricted use, distribution, and reproduction in any medium, provided the original work is properly cited.

\begin{abstract}
Although the number of elderly patients requiring dialysis has increased, data regarding the prognosis of elderly patients undergoing hemodialysis are limited. In the present study, prognosis in Japanese hemodialysis patients aged $\geq 80$ years was evaluated. From January 1988 to July 2013, 1144 consecutive patients with end-stage renal disease required renal replacement therapy at our institution; of these, 141 were aged $\geq 80$ years. These patients' charts were retrospectively reviewed for relevant clinical variables and survival time. The life expectancies table from the National Vital Statistics database was used, and prognostic factors were assessed by multivariate analysis. In total, 107 deaths (76\%) were recorded during the study period. The median survival time and estimated life-shortening period in the patients were 2.6 years and -5.3 years, respectively. Eastern Cooperative Oncology Group Performance Status and hemoglobin level were revealed as prognostic factors in the multivariate analysis. Estimates of prognosis and prognostic factors may provide useful information for physicians as well as elderly patients with end-stage kidney disease.
\end{abstract}

\section{Introduction}

As the Japanese population continues to age and the prevalence of chronic kidney disease increases [1,2], clinicians are frequently faced with the decision of whether or not to initiate renal replacement therapy for their patients. According to the latest nationwide review conducted by the Japanese Society for Dialysis Therapy in 2012, 309,946 patients were on dialysis, and dialysis was initiated in 38,165 new patients that year [3]. Along with this increase in the number of dialysis patients, the number of older patients ( $\geq 80$ years) undergoing hemodialysis treatment each year has also increased. In 2004, $14 \%$ of all dialysis patients in Japan were $\geq 80$ years old. These figures were $16 \%$ in $2006,18 \%$ in $2008,19 \%$ in 2010 , and $22 \%$ in 2012, whereas the number of Japanese patients aged 70-79 years receiving dialysis has remained unchanged in the last decade (Figure 1) [3].

Many clinicians believe that age is a barrier for initiation of renal replacement therapy because dialysis in elderly patients has been associated with an increased risk of mortality. However, data regarding the prognosis of elderly patients undergoing hemodialysis are limited. Thus, in the present study, the median survival time in hemodialysis patients aged $\geq 80$ years was evaluated, and the period of time by which these patients' lives were shortened (life-shortening period) was estimated using a life expectancies table from the National Vital Statistics data for 2008 [4]. Prognostic factors were then assessed by multivariate analysis. 
The prevalence of elderly patients

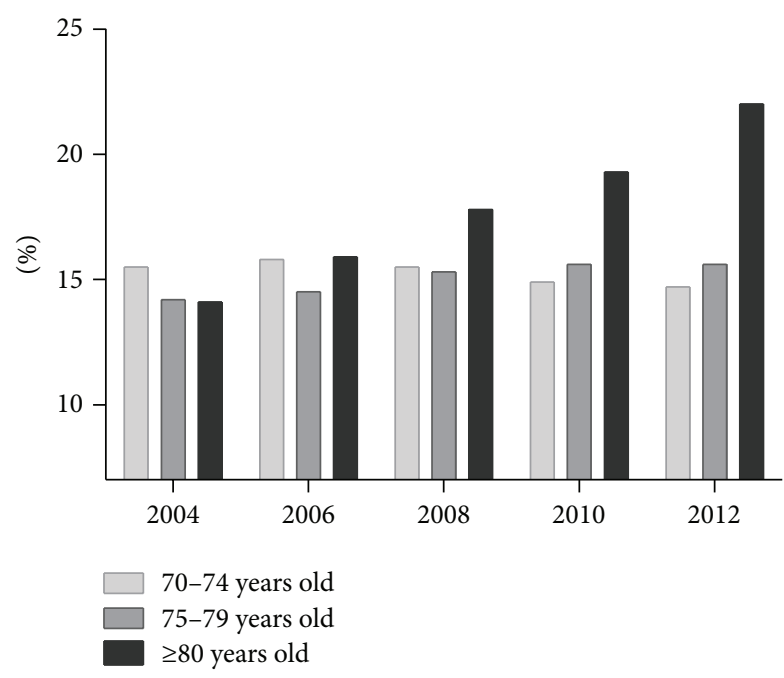

FIGURE 1: Prevalence of elderly patients receiving dialysis treatment in the overall Japanese population according to age.

\section{Materials and Methods}

This study was conducted in accordance with the ethical standards of the Declaration of Helsinki and approved by the Institutional Ethics Committee. From January 1988 to July 2013, 1144 consecutive patients with end-stage renal disease required renal replacement therapy at the Oyokyo Kidney Research Institute, Hirosaki, Japan. Of these, 141 were aged $\geq 80$ years. Patient charts were retrospectively reviewed for relevant clinical variables and survival time.

The following data were collected for use in the analyses: patient age, gender, body mass index, and blood pressure; hemoglobin, serum albumin, phosphorus, potassium, and corrected calcium levels; blood urea nitrogen level and estimated glomerular filtration rate (eGFR); concomitant use of antihypertensive drugs (angiotensin-converting enzyme inhibitors, angiotensin receptor blockers, or calcium blockers); and presence or absence of diabetes mellitus or cerebral and cardiovascular disease (cerebral infarction, heart failure, myocardial infarction, and angina pectoris) at the initial visit. The eGFR was calculated using values for age, gender, and serum creatinine levels and the equation shown below [5]. This eGFR equation for Japanese patients is a modified version of the abbreviated Modification of Diet in Renal Disease Study formula: eGFR $\mathrm{mL} / \mathrm{min} / 1.73 \mathrm{~m}^{2}=194 \times$ $\mathrm{sCr}^{-1.094} \times$ age $^{-0.287}(\times 0.739$, if female $)[6]$. Patient general health status before dialysis initiation was evaluated on the Eastern Cooperative Oncology Group Performance Status scale (ECOG-PS) [7].

The life expectancy is calibrated using the life expectancies table [4] based on expected age of death on specific age at dialysis initiation. To evaluate differences in life expectancy between these patients and the general population, lifeshortening periods were calculated according to the following formula: expected age of death on specific age at dialysis initiation-the actual age of death.
2.1. Basic Policies for Indication of Renal Replacement Therapy. Hemodialysis is the standard treatment strategy for renal replacement therapy in elderly patients ( $\geq 80$ years) with end-stage renal disease at our institution. The purpose of this treatment is to minimize present suffering, gain time to consider continuation of renal replacement therapy and its alternatives, and ensure renal survival. Patients who refuse renal replacement therapy and those with systemic comorbidities, extremely advanced heart failure, or severe complications are designated as "not indicated for treatment."

2.2. Follow-Up Schedule. All patients were routinely followed up for thrice-weekly hemodialysis with standard care according to the guidelines of the Japanese Society for Dialysis Therapy for the management of patients on chronic hemodialysis $[8,9]$ and tracked until the occurrence of death, loss of follow-up, or end of study (July 31, 2013), whichever came first. Erythropoiesis-stimulating agents were used when hemoglobin level was lower than $10 \mathrm{~g} / \mathrm{L}$ in all patients. The target hemoglobin level was 10-11 g/L.

2.3. Statistical Analysis. Patient survival was evaluated using the Kaplan-Meier method. Variables were compared among groups using Student's $t$-test or Mann-Whitney $U$ test. Age, gender, body mass index, blood pressure, hemoglobin, serum albumin, phosphorus, potassium, and corrected calcium levels, blood urea nitrogen, estimated glomerular filtration rate (eGFR), concomitant use of antihypertensive drugs, presence or absence of diabetes mellitus, and cerebral and cardiovascular disease were analyzed using stepwise Cox regression multivariate analysis to determine independent predictors for overall survival. After these factors were identified, a receiver operating characteristic (ROC) curve was used to determine the optimal cut-off value for prognosis. This value was calculated using the following formula [10]: $(1-\text { sensitivity })^{2}+$ $(1-\text { specificity })^{2}$. Each patient was categorized according to the number of risk factors identified in the Cox regression multivariate analysis to evaluate the predictive potential of risk criteria for prognosis. Each positively identified risk factor was given a score of 1 , and scores for all other risk factors were summed. Patients were classified into three groups according to the number of risk factors: the low-risk group (patients with no risk factors), the intermediate-risk group (one risk factor), and the high-risk group (two risk factors). The statistical significance of the differences between the three groups was evaluated by the log rank test.

All statistical analyses were performed using the SPSS software package version 19.0 (SPSS, Chicago, IL, USA) and GraphPad Prism version 5.03 (GraphPad Software, San Diego, CA, USA). A $P$ value of $<0.05$ was considered statistically significant.

\section{Results}

Characteristics of all 1144 dialysis patients are summarized in Table 1. The age distribution of patients was as follows: 129 (11\%), 202 (18\%), 324 (28\%), 348 (30\%), and $141(12 \%)$ 
TABLE 1: Characteristics of 1144 dialysis patients included in this study.

\begin{tabular}{|c|c|c|c|c|c|c|}
\hline & All & $<50$ years & $50 \mathrm{~s}$ & $60 \mathrm{~s}$ & $70 \mathrm{~s}$ & $\geq 80 \mathrm{~s}$ \\
\hline Number of patients & 1144 & 129 & 202 & 324 & 348 & 141 \\
\hline Male/female & $714 / 430$ & $78 / 51$ & $137 / 65$ & 209/115 & $217 / 131$ & $73 / 68$ \\
\hline Age at start dialysis (years) & $65.8 \pm 12.9$ & $41.1 \pm 7.2$ & $55.8 \pm 2.8$ & $64.7 \pm 2.9$ & $74.5 \pm 3.1$ & $84.2 \pm 3.1$ \\
\hline Survival after dialysis initiation (years) & 6.8 & 20 & 9.1 & 7.7 & 4.4 & 2.6 \\
\hline Life expectancy (years) & 18.6 & 40.2 & 28.1 & 20.2 & 13.4 & 7.7 \\
\hline Life-shortening periods (years) & -11.6 & -30.1 & -22.5 & -14.6 & -9.4 & -5.3 \\
\hline Deceased patients & $667(58 \%)$ & $39(30 \%)$ & $108(53 \%)$ & $182(56 \%)$ & $230(66 \%)$ & $107(76 \%)$ \\
\hline \multicolumn{7}{|l|}{ Cause of death } \\
\hline Cerebro-cardiovascular disease & $235(35 \%)$ & $14(36 \%)$ & $41(38 \%)$ & $75(41 \%)$ & $76(33 \%)$ & $29(27 \%)$ \\
\hline Infections & $167(25 \%)$ & $7(18 \%)$ & $27(25 \%)$ & $37(20 \%)$ & $61(27 \%)$ & $35(33 \%)$ \\
\hline Cancer & $88(13 \%)$ & $5(13 \%)$ & $14(13 \%)$ & $25(14 \%)$ & $30(13 \%)$ & $14(13 \%)$ \\
\hline Others & $132(20 \%)$ & $7(18 \%)$ & $17(16 \%)$ & $30(16 \%)$ & $22(10 \%)$ & $22(21 \%)$ \\
\hline Unknown & $44(7 \%)$ & $6(15 \%)$ & $9(8 \%)$ & $15(8 \%)$ & $7(3 \%)$ & $7(6.5 \%)$ \\
\hline
\end{tabular}

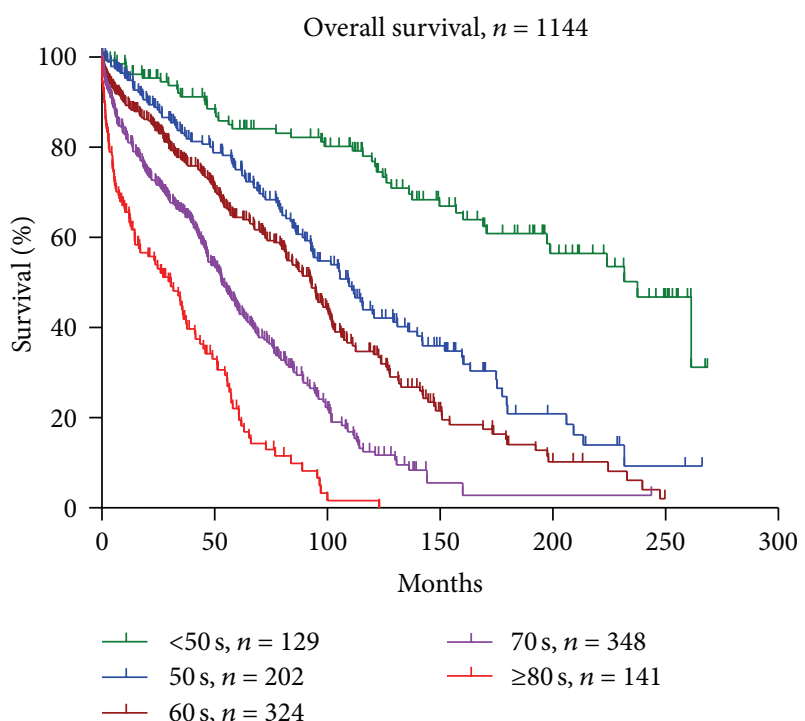

FIGURE 2: Overall survival in 1144 dialysis patients according to age.

in the following age groups: $<50$ years $(<50 \mathrm{~s}), 50-59$ years (50s), 60-69 years ( $60 \mathrm{~s}), 70-79$ years $(70 \mathrm{~s})$, and $\geq 80$ years $(\geq 80 \mathrm{~s})$, respectively. The median survival times were $20,9.1$, $7.7,4.4$, and 2.6 years in the same age groups (Figure 2). The most frequent and second most frequent causes of death were cerebro-cardiovascular disease and infectious diseases, respectively, except for patients in the $\geq 80$ s group. Mortality increased with age. The estimated mean life-shortening values were $-30.1,-22.5,-14.6,-9.4$, and -5.3 years, respectively, in deceased patients in the five age groups.

Characteristics of the 141 patients in the $\geq 80$ s group are summarized in Table 2. All patients were undergoing hemodialysis, and their median age was 83 years. The median survival times in patients aged $80-84,85-89$, and $>90$ years old were 3.0, 2.5, and 0.9 years, respectively (Figure 3 ). Among the 141 patients, 107 deaths (76\%) were recorded as of

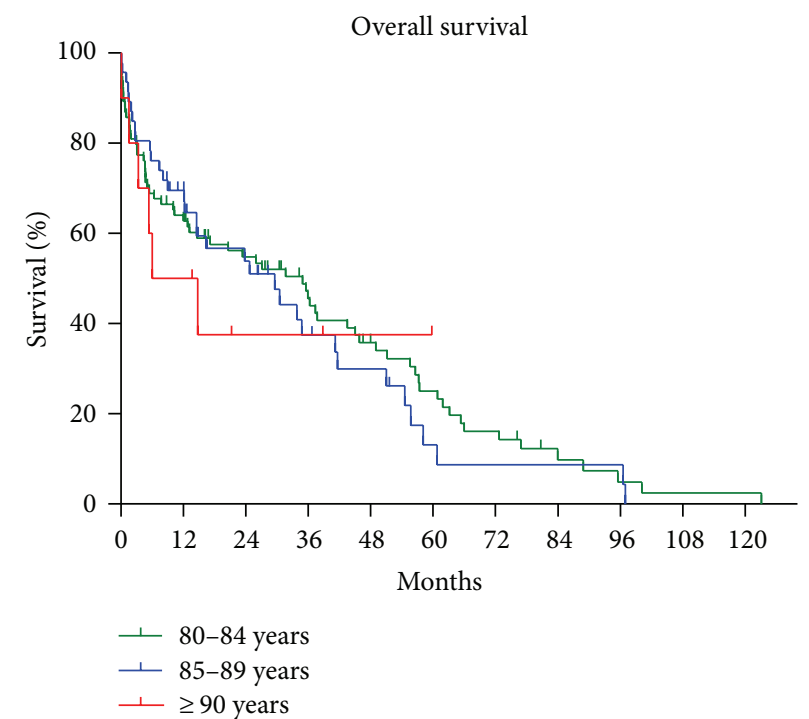

Number at risk

\begin{tabular}{lllllllll}
\hline $80-84$ years 84 & 52 & 40 & 28 & 20 & 14 & 3 & 1 \\
$85-89$ years 47 & 30 & 20 & 12 & 9 & 3 & 2 & 0 \\
$\geq 90$ years & 10 & 6 & 3 & 3 & 2 & 1 & & \\
\hline
\end{tabular}

FIGURE 3: Overall survival in 144 dialysis patients aged $\geq 80$ years. The median survivals in the age groups of $80-84,85-89$, and $>90$ years were $3.0,2.5$, and 0.9 years, respectively. There were no significant differences in survival among the groups.

July 31, 2013. The highest number of patients who died within 1 year was $49(46 \%)$. The most frequent causes of death were infectious disease in 35 patients (33\%), and the second most frequent causes of death were cerebro-cardiovascular disease in 29 patients $(27 \%)$. The median estimated life-shortening period was -5.3 years in deceased patients aged $\geq 80$ years. 
TABLE 2: Characteristics of dialysis patients aged $\geq 80$ years.

\begin{tabular}{|c|c|c|c|c|}
\hline & All & Living & Deceased & $P$ value \\
\hline Number of patients & 141 & 34 & 107 & \\
\hline Male/female & $73 / 68$ & $17 / 17$ & $56 / 15$ & 0.0026 \\
\hline Duration from first visit to dialysis initiation (months) & $4.2 \pm 13$ & $8.3 \pm 18$ & $4.2 \pm 11$ & 0.2154 \\
\hline Age at start dialysis (years) & $84 \pm 3.1$ & $84.5 \pm 3.6$ & $84.1 \pm 3.0$ & 0.5540 \\
\hline Deceased within 1 year & & & $49(46 \%)$ & \\
\hline ECOG-PS at dialysis initiation & $2.2 \pm 1.3$ & $1.2 \pm 1.4$ & $2.2 \pm 1.2$ & 0.0004 \\
\hline Cerebro-cardiovascular disease & $88(62 \%)$ & $20(59 \%)$ & $68(64 \%)$ & 0.6200 \\
\hline Diabetes mellitus & $49(35 \%)$ & $11(32 \%)$ & $38(36 \%)$ & 0.7360 \\
\hline Mean blood pressure (mmHg) & $117 \pm 21$ & $114 \pm 22$ & $117 \pm 22$ & 0.4817 \\
\hline Systolic & $156 \pm 31.7$ & $159 \pm 34.1$ & $156 \pm 31.1$ & 0.7437 \\
\hline Diastolic & $78 \pm 16$ & $69.6 \pm 15.6$ & $77.6 \pm 16.2$ & 0.0132 \\
\hline Body mass index & $22 \pm 4.3$ & $23.2 \pm 4.0$ & $22.2 \pm 4.4$ & 0.2319 \\
\hline Hemoglobin $(\mathrm{g} / \mathrm{L})$ & $8.9 \pm 1.9$ & $9.2 \pm 1.9$ & $8.9 \pm 1.9$ & 0.4054 \\
\hline BUN (mg/dL) & $84 \pm 33$ & $76.7 \pm 33.7$ & $83.5 \pm 33.1$ & 0.3071 \\
\hline eGFR & $8.4 \pm 4.5$ & $7.9 \pm 4.1$ & $8.4 \pm 4.7$ & 0.5604 \\
\hline Albumin (mg/dL) & $3.4 \pm 0.6$ & $3.5 \pm 0.5$ & $3.4 \pm 0.7$ & 0.1813 \\
\hline Phosphorus (mg/dL) & $5.3 \pm 1.6$ & $5.0 \pm 1.3$ & $5.3 \pm 1.7$ & 0.2801 \\
\hline Potassium $(\mathrm{mEq} / \mathrm{L})$ & $4.8 \pm 1.0$ & $5.0 \pm 0.8$ & $4.8 \pm 1.0$ & 0.3065 \\
\hline Calcium (mg/dL) & $8.8 \pm 0.7$ & $8.4 \pm 0.6$ & $8.1 \pm 0.8$ & 0.0110 \\
\hline
\end{tabular}

Life-shortening periods $(n=107)$

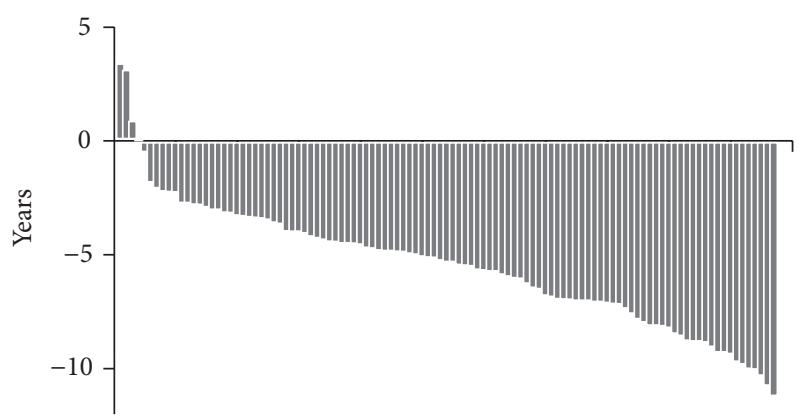

FIGURE 4: Life-shortening periods in dialysis patients aged $\geq 80$ years. The median estimated life-shortening periods were -5.3 years in deceased patients aged $\geq 80$ years.

Only three patients survived longer than the general life expectancy in the Japanese population (Figure 4).

Results of the multivariate analysis revealed ECOGPS and hemoglobin levels as significant prognostic factors in elderly patients undergoing hemodialysis (Table 3). Risk criteria were constructed using these significant independent risk factors for stratification of patient survival. The optimal cut-off points calculated from ROC curves for ECOG-PS and hemoglobin level were $>1$ and $<9.55 \mathrm{~g} / \mathrm{L}$, respectively. Patients were then categorized according to the number of independent risk factors for overall survival. This risk classification indicated significantly poor prognoses in the intermediate- and high-risk groups compared with those in the low-risk group $(P=0.0059)$ (Figure 5). The median sur- vival time in the low-risk group was 63 months, whereas that in the other groups was 23-24 months.

\section{Discussion}

In Japan, the number of elderly patients with end-stage renal disease requiring dialysis treatment continues to grow. Data from the latest Japanese Society for Dialysis Therapy database (2012) showed that the number of dialysis patients aged $\geq 80$ years increased by more than $8 \%$ between 2005 and 2013 [3], and $22 \%$ of all dialysis patients were aged $\geq 80$ years. Several studies have particularly evaluated the indications and outcomes of maintenance dialysis in elderly patients [1118]; however, no reports have examined prognosis in these patients in Japan. In this study, survival outcome in elderly Japanese hemodialysis patients aged $\geq 80$ years was compared with that in the general population. The median survival time of 2.6 years was comparable to that in previous reports of approximately $2.4-3.2$ years $[13,16,17,19]$.

Japan is a country where life expectancy is high [4, 20]. Thus, in the general population, life expectancy among patients aged $\geq 80$ years is 7.6 years. The estimated median life-shortening period calculated from the life expectancies table was -5.3 years in deceased patients. These data could not be compared with those from other industrialized countries; however, comparison using the estimated median lifeshortening periods from various countries may reveal social differences, including those related to medical or insurance systems. Further studies are required on this issue. Because elderly patients on hemodialysis constitute a heterogeneous 
TABLE 3: Results of univariate and multivariate Cox regression analyses for overall survival in dialysis patients aged $\geq 80$ years.

\begin{tabular}{|c|c|c|c|c|c|c|c|}
\hline & \multicolumn{3}{|c|}{ Univariate analysis } & & \multicolumn{3}{|c|}{ Multivariate analysis } \\
\hline & $P$ value & HR & $95.0 \% \mathrm{CI}$ & & $P$ value & HR & $95.0 \% \mathrm{CI}$ \\
\hline Age (years) & 0.443 & 1.024 & $0.96-1.09$ & & & & \\
\hline Cerebro-cardiovascular disease & 0.163 & 1.327 & $0.89-1.98$ & & & & \\
\hline Diabetes mellitus & 0.976 & 0.994 & $0.67-1.46$ & & & & \\
\hline ECOG-PS & 0.000 & 1.327 & $1.15-1.54$ & ECOG-PS & 0.004 & 1.27 & $1.08-1.49$ \\
\hline Mean blood pressure (mmHg) & 0.164 & 0.994 & $0.99-1.01$ & & & & \\
\hline Body mass index & 0.060 & 0.961 & $0.92-1.01$ & & & & \\
\hline Hemoglobin $(\mathrm{g} / \mathrm{L})$ & 0.231 & 1.070 & $0.96-1.20$ & Hemoglobin & 0.040 & 1.13 & $1.01-1.28$ \\
\hline BUN (mg/dL) & 0.177 & 1.004 & $0.99-1.01$ & & & & \\
\hline $\mathrm{eGFR}\left(\mathrm{mL} / \mathrm{min} . / 1.73 \mathrm{~m}^{2}\right)$ & 0.782 & 1.006 & $0.97-1.05$ & & & & \\
\hline Albumin (mg/dL) & 0.013 & 0.652 & $0.47-0.91$ & Albumin & 0.067 & 0.71 & $0.48-1.03$ \\
\hline Phosphorus (mg/dL) & 0.068 & 1.132 & $0.99-1.29$ & & & & \\
\hline Potassium $(\mathrm{mEq} / \mathrm{L})$ & 0.265 & 1.133 & $0.91-1.41$ & & & & \\
\hline Calcium (mg/dL) & 0.861 & 1.024 & $0.79-1.33$ & & & & \\
\hline Antihypertensive agents & 0.275 & 1.324 & $0.80-2.19$ & & & & \\
\hline
\end{tabular}

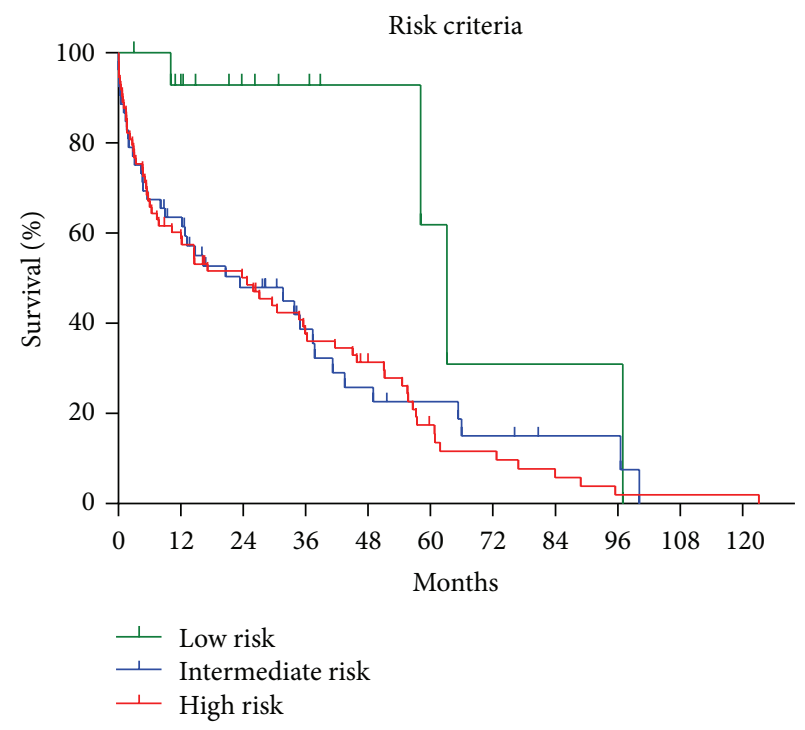

Number at risk

\begin{tabular}{lccccccccc}
\hline Low risk & 15 & 12 & 8 & 6 & 4 & 3 & 2 & 2 & 2 \\
Inter. risk & 53 & 32 & 21 & 13 & 9 & 7 & 5 & 3 & 2 \\
High risk & 73 & 43 & 34 & 25 & 19 & 10 & 6 & 4 & 2 \\
\hline
\end{tabular}

FIGURE 5: Risk classification for prognosis in dialysis patients aged $\geq 80$ years. Each patient was categorized according to the number of selected risk factors using Cox regression multivariate analysis to evaluate the predictive potential of risk criteria for prognosis. Each existing risk factor was scored as 1, and scores for all the other risk factors were summated. Patients were classified into three groups according to the number of risk factors: the low-risk group (patients with no risk factor), the intermediate-risk group (1 risk factors), and the high-risk group (2 risk factors).

group of patients, their chronological age may not necessarily correlate with their biological age. Several risk factors pertain to elderly hemodialysis patients aged $\geq 80$ years, including body mass index, late referral to a nephrologist, poor performance status, presence of peripheral vascular disease [17], older age, acute congestive heart failure, any walking impairment, and hemoglobin level $(<10 \mathrm{~g} / \mathrm{L})$ [18]. Establishing a standard risk-associated classification system for planning dialysis initiation may help clinicians in treatment decision-making. In the multivariate Cox analysis, independent predictors for overall survival were ECOGPS $\geq 1$ and hemoglobin level was $\leq 9.55 \mathrm{~g} / \mathrm{L}$. Based on these risk criteria, survival rates were significantly lower in the intermediate- and high-risk groups.

Because of technological advancements in dialysis treatment, old age is no longer considered as a contraindication in 
most industrialized countries [15-18, 21, 22]. Recent studies suggested that dialysis provides a survival benefit compared with conservative management for patients with stages 4-5 chronic kidney disease over the age of 75 years [23-25]. However, dialysis may or may not offer a substantial prolongation of life expectancy with an acceptable quality of life (QOL) among elderly patients. QOL is very important for older patients for whom renal transplantation is an unlikely option. However, very few studies have addressed QOL issues in elderly patients with end-stage renal disease because of the controversial nature of this decision [19, 21, 26]. Lamping et al. reported no significant differences in QOL scores between elderly dialysis patients and elderly individuals in the general population in the UK and USA [26]. In contrast, Tamura et al. reported an association between dialysis initiation and substantial and sustained decline in functional status among nursing home residents with end-stage renal disease [27]. Carson et al. demonstrated prolonged survival for elderly patients ( $\geq 70$ years of age) on dialysis compared with those conservatively treated. However, survival time in patients who were conservatively treated may be substantial, considering that a similar number of hospital-free days was recorded for both groups of patients [19]. Benefits and disadvantages of dialysis in elderly patients and its effects on QOL continue to be debated. The particular needs and traditional customs of the populations in each individual country or region must be considered. In addition, because randomized controlled trials comparing outcomes and QOL in patients receiving renal replacement therapy compared with those conservatively treated are not feasible, observational studies remain the only means by which treatment methods can be compared.

The present study has several important limitations, including its retrospective nature, small sample size, and the inclusion of patients within a single institution. We could not address the total dose and its influences of erythropoiesisstimulating agents. There might be association between the dose of erythropoiesis-stimulating agents and patients' death. Higher use of erythropoiesis-stimulating agents for poor responder or excessively higher hemoglobin levels may link to poor prognosis. Therefore, the results of this study cannot be generalized. In addition, the primary question as to who will receive survival and comprehensive benefits may remain unanswered. In elderly patients undergoing hemodialysis, details of patient characteristics such as late referral, presence of peripheral vascular disease, frailty, and information regarding QOL were lacking and must therefore be considered in future studies.

Despite these limitations, the present study provided some useful information. Shortening of life expectancy was investigated using the National Vital Statistics survey database for Japan in 2008. Because medical and insurance systems differ among countries, decision-making regarding dialysis initiation and its indications may also differ. Because Japan is a country with a high life expectancy rate $[4,20]$, life expectancy in elderly patients should be calculated using life expectancy tables in each individual country or region. The present study is the first to investigate the shortening of life expectancy in Japanese hemodialysis patients aged $\geq 80$ years.

\section{Conclusion}

In conclusion, the results of this study shed light on the prognosis of elderly dialysis patients in Japan, whose number is increasing. Our observations suggest that old age is no longer considered as a contraindication, and hemodialysis initiation is acceptable for the rather elderly patients with end-stage renal disease in consideration of risk factors. Further clinical study is required to determine the most appropriate treatment for elderly patients with end-stage renal failure. A new evaluation system is required to aid decision-making between conservative or renal replacement therapy with consideration of comorbidities, health status, and patient preferences in the elderly Japanese population.

\section{Conflict of Interests}

All authors declare that there is no conflict of interests regarding the publication of this paper.

\section{Acknowledgment}

This work was supported by a Grant-in-Aid for Scientific Research 23791737, from the Japan Society for the Promotion of Science.

\section{References}

[1] E. Imai, M. Horio, K. Iseki et al., "Prevalence of chronic kidney disease $(\mathrm{CKD})$ in the Japanese general population predicted by the MDRD equation modified by a Japanese coefficient," Clinical and Experimental Nephrology, vol. 11, no. 2, pp. 156-163, 2007.

[2] E. Imai, M. Horio, T. Watanabe et al., "Prevalence of chronic kidney disease in the Japanese general population," Clinical and Experimental Nephrology, vol. 13, no. 6, pp. 621-630, 2009.

[3] Patient Registration Committee, An Overview of Regular Dialysis Treatment in Japan, Japanese Society of Dialysis Therapy, 2012.

[4] Statistics and Information Department, Life Expectancies at Specified Ages, Vital Statistics of Japan, Ministers' Secretariat, Ministry of Health, Labour and Welfare, 2008.

[5] S. Matsuo, E. Imai, M. Horio et al., "Revised Equations for Estimated GFR From Serum Creatinine in Japan," The American Journal of Kidney Diseases, vol. 53, no. 6, pp. 982-992, 2009.

[6] G. Manjunath, M. J. Sarnak, and A. S. Levey, "Prediction equations to estimate glomerular filtration rate: an update," Current Opinion in Nephrology and Hypertension, vol. 10, no. 6, pp. 785-792, 2001.

[7] M. M. Oken, R. H. Creech, and T. E. Davis, "Toxicology and response criteria of the eastern cooperative oncology group," The American Journal of Clinical Oncology: Cancer Clinical Trials, vol. 5, no. 6, pp. 649-655, 1982.

[8] M. Fukagawa, K. Yokoyama, F. Koiwa et al., "Clinical practice guideline for the management of chronic kidney diseasemineral and bone disorder," Therapeutic Apheresis and Dialysis, vol. 17, no. 3, pp. 247-288, 2013.

[9] H. Hirakata, K. Nitta, M. Inaba et al., "Japanese society for dialysis therapy guidelines for management of cardiovascular 
diseases in patients on chronic hemodialysis," Therapeutic Apheresis and Dialysis, vol. 16, no. 5, pp. 387-435, 2012.

[10] A. K. Akobeng, "Understanding diagnostic tests 3: receiver operating characteristic curves," Acta Paediatrica, vol. 96, no. 5, pp. 644-647, 2007.

[11] P. L. Neves, A. Sousa, I. Bernardo et al., "Chronic haemodialysis for very old patients," Age and Ageing, vol. 23, no. 5, pp. 356-359, 1994.

[12] L. Vandelli, G. Medici, S. Perrone, and E. Lusvarghi, "Haemodialysis therapy in the elderly," Nephrology Dialysis Transplantation, vol. 11, no. 9, pp. 89-94, 1996.

[13] B. Röhrich, D. von Herrath, G. Asmus, and K. Schaefer, "The elderly dialysis patient: management of the hospital stay," Nephrology Dialysis Transplantation, vol. 13, no. 7, pp. 69-72, 1998.

[14] K. Schaefer and B. Röhrich, "The dilemma of renal replacement therapy patients over 80 years of age. Dialysis should not be withheld," Nephrology Dialysis Transplantation, vol. 14, no. 1, pp. 35-36, 1999.

[15] S. K. Munshi, N. Vijayakumar, N. A. Taub, H. Bhullar, T. C. N. Lo, and G. Warwick, "Outcome of renal replacement therapy in the very elderly," Nephrology Dialysis Transplantation, vol. 16, no. 1, pp. 128-133, 2001.

[16] U. N. Peri, A. Z. Fenves, and J. P. Middleton, "Improving survival of octogenarian patients selected of haemodialysis," Nephrology Dialysis Transplantation, vol. 16, no. 11, pp. 2201-2206, 2001.

[17] D. Joly, D. Anglicheau, C. Alberti et al., "Octogenarians reaching end-stage renal disease: cohort study of decision-making and clinical outcomes," Journal of the American Society of Nephrology, vol. 14, no. 4, pp. 1012-1021, 2003.

[18] B. Faller, J. B. Beuscart, L. Frimat, and The Association des néphrologues de l'Est, "Competing-risk analysis of death and dialysis initiation among elderly ( $\geq 80$ years) newly referred to nephrologists: a French prospective study," BMC Nephrology, vol. 14, article 103, 2013.

[19] R. C. Carson, M. Juszczak, A. Davenport, and A. Burns, "Is maximum conservative management an equivalent treatment option to dialysis for elderly patients with significant comorbid disease?" Clinical Journal of the American Society of Nephrology, vol. 4, no. 10, pp. 1611-1619, 2009.

[20] World Health Organization and Ebrary Inc., World Health Statistics 2008, World Health Organization, Geneva, Switzerland, 2008.

[21] A. Smyth, "End-stage renal disease and renal replacement therapy in older patients," Nephro-Urology Monthly, vol. 4, no. 2, pp. 425-430, 2012.

[22] M. K. Tamura and W. C. Winkelmayer, "Treated and untreated kidney failure in older adults: what's the right balance?" The Journal of the American Medical Association, vol. 307, no. 23, pp. 2545-2546, 2012.

[23] F. E. M. Murtagh, J. E. Marsh, P. Donohoe, N. J. Ekbal, N. S. Sheerin, and F. E. Harris, "Dialysis or not? A comparative survival study of patients over 75 years with chronic kidney disease stage 5," Nephrology Dialysis Transplantation, vol. 22, no. 7, pp. 1955-1962, 2007.

[24] S. M. Chandna, M. Da Silva-Gane, C. Marshall, P. Warwicker, R. N. Greenwood, and K. Farrington, "Survival of elderly patients with stage $5 \mathrm{CKD}$ : comparison of conservative management and renal replacement therapy," Nephrology Dialysis Transplantation, vol. 26, no. 5, pp. 1608-1614, 2011.
[25] N. Demoulin, C. Beguin, L. Labriola, and M. Jadoul, "Preparing renal replacement therapy in stage $4 \mathrm{CKD}$ patients referred to nephrologists: a difficult balance between futility and insufficiency. A cohort study of 386 patients followed in Brussels," Nephrology Dialysis Transplantation, vol. 26, no. 1, pp. 220-226, 2011.

[26] D. L. Lamping, N. Constantinovici, P. Roderick et al., "Clinical outcomes, quality of life, and costs in the North Thames dialysis study of elderly people on dialysis: a prospective cohort study," The Lancet, vol. 356, no. 9241, pp. 1543-1550, 2000.

[27] M. K. Tamura, K. E. Covinsky, G. M. Chertow, K. Yaffe, C. S. Landefeld, and C. E. McCulloch, "Functional status of elderly adults before and after initiation of dialysis," The New England Journal of Medicine, vol. 361, no. 16, pp. 1539-1547, 2009. 


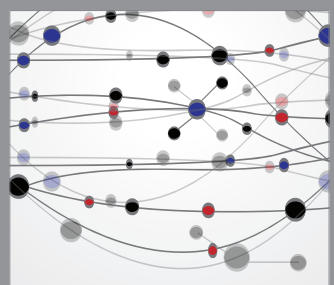

The Scientific World Journal
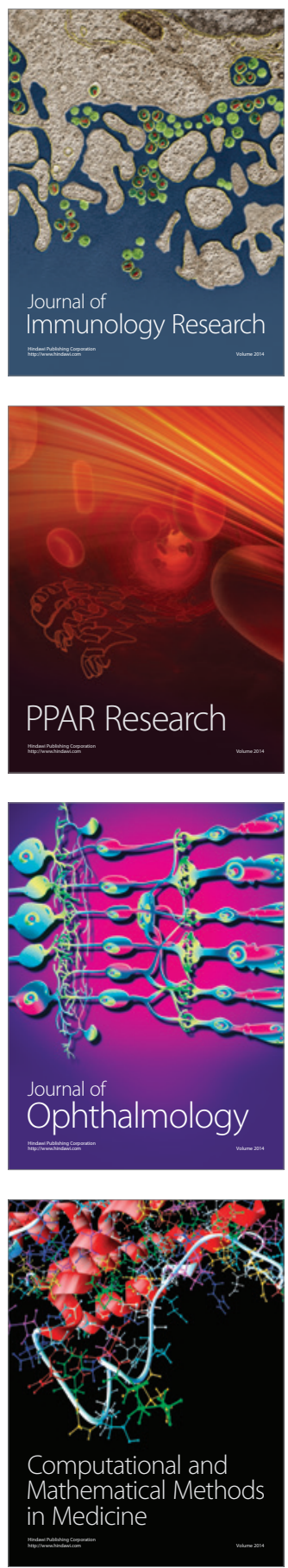

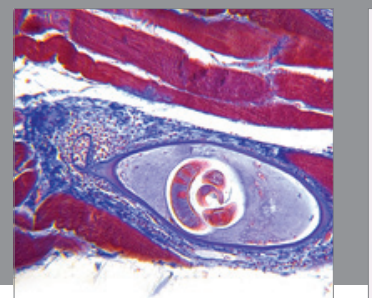

Gastroenterology

Research and Practice
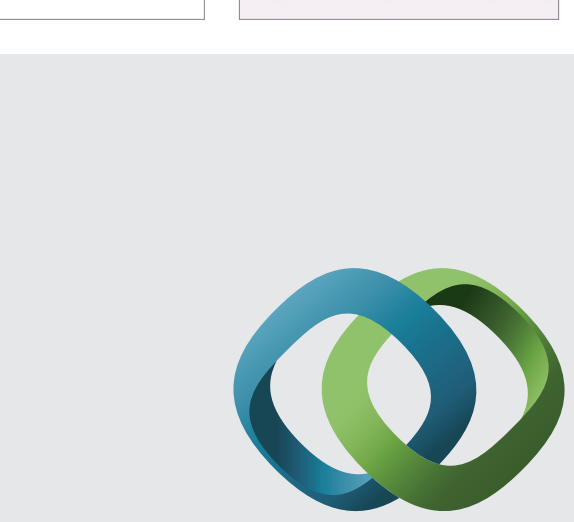

\section{Hindawi}

Submit your manuscripts at

http://www.hindawi.com
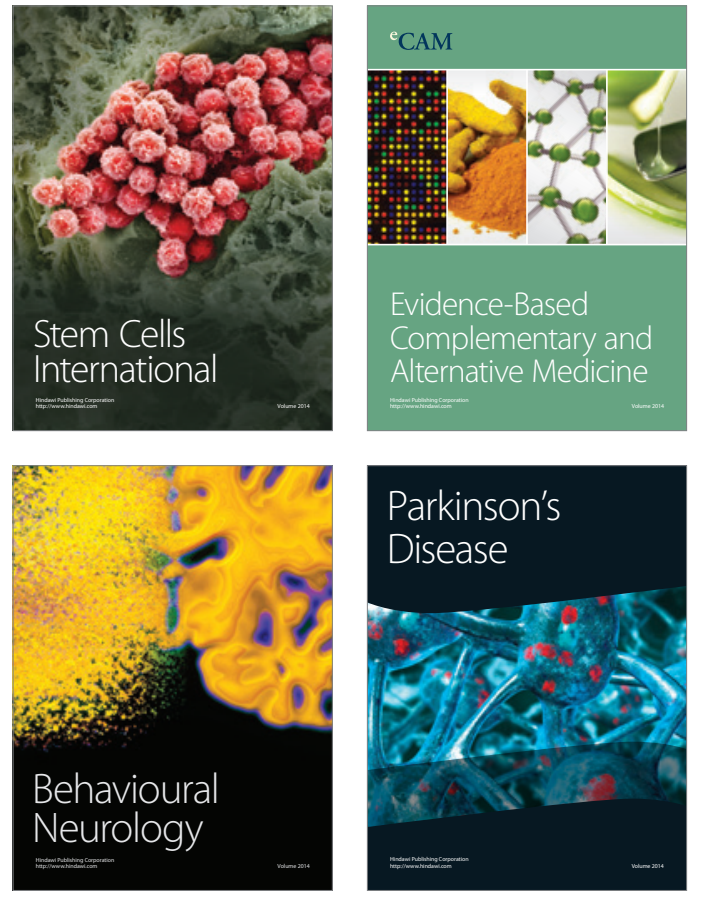
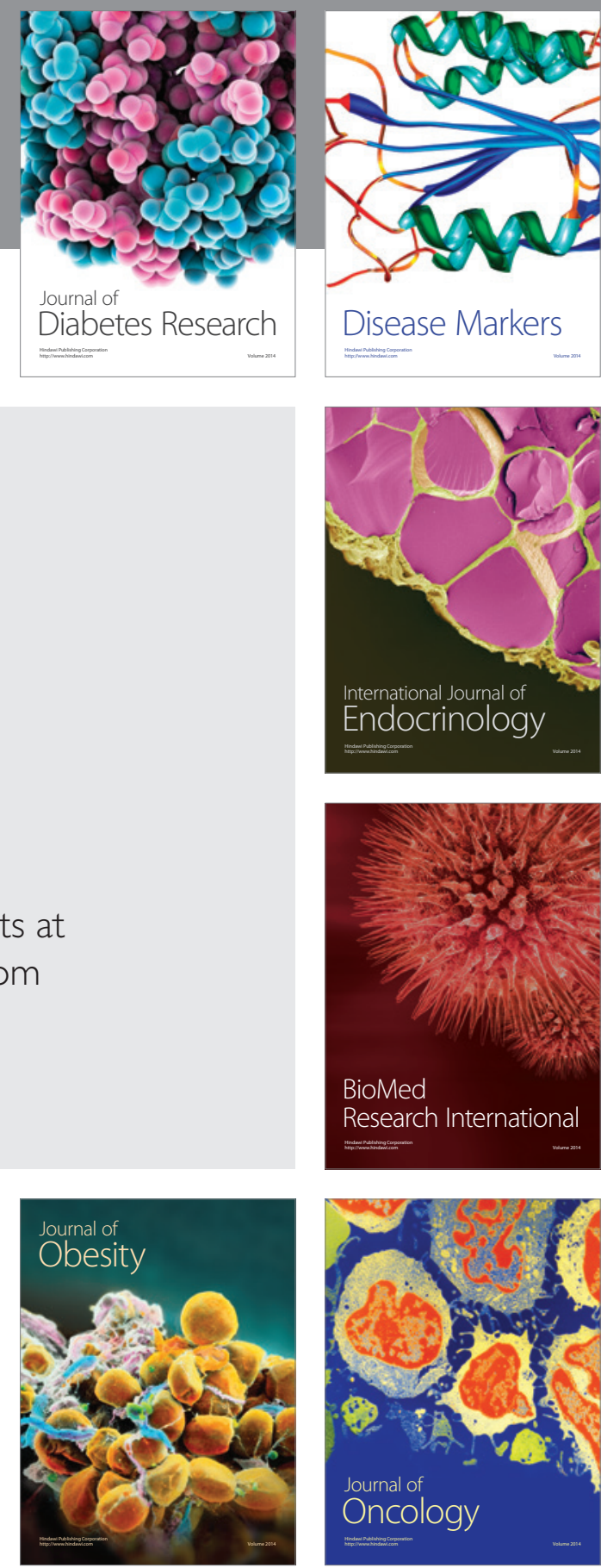

Disease Markers
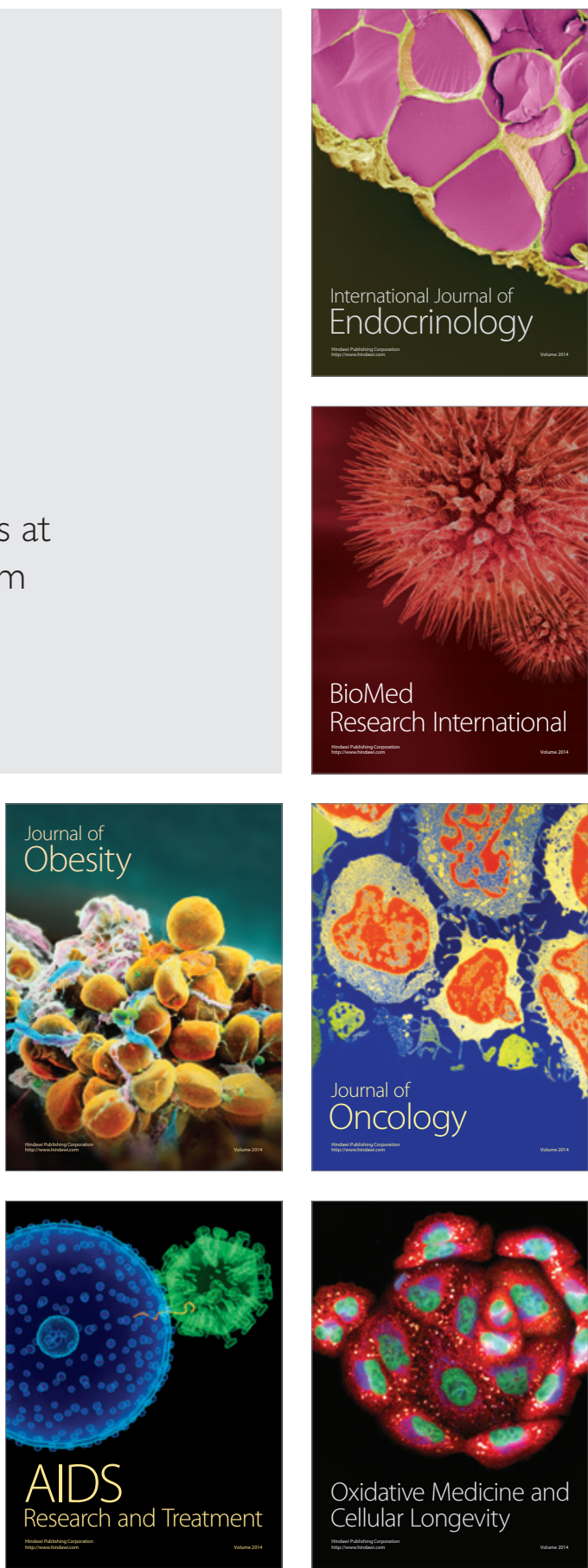